\title{
Evaluation on Total phenolic compound content and Resveratrol content in Thai YaDong
}

\author{
Pornpimol Muangthai, ${ }^{1}$ Jaruwan Daengchat, ${ }^{1}$ Jaturong Congcharoen ${ }^{1}$ \\ ${ }^{I}$ (Department of Chemistry,Srinakharinwirot University,Bangkok , Thailand)
}

\begin{abstract}
The aim of this work was to analyse total phenolic content and resveratrol content in Thai Yadong to evaluate the quality of commercial Thai YaDong. YaDong were prepared by fermentation of ten herbal plants in white spiritual liquor and $80 \%$ ethanol in laboratory, then total phenolic content was analysed by spectrohotometry.and resveratrol was analysed using high performance liquid chromatography. The result showed that each medicinal plant that extracted by ethanol and white spiritual liquor contained the total phenolic compound in the range of $2.00-74.42 \mathrm{~g} / \mathrm{L}$ and $1.20-76.82 \mathrm{~g} / \mathrm{L}$, respectively. The 10 medicinal plants also has an important substance as resveratrol in the range of $0.2-7 \mathrm{ppm}$. The laboratory YaDong showed the higher value of total phenolic compound content more than commercial YaDong.The total phenolic compound content in laboratory YaDong was in the range of $62.50-71.20 \mathrm{~g} / \mathrm{L}$, the commercial YaDong has the total phenolic compound in the range of 5.00-41.00 g/L.The resveratrol content in laboratory YaDong also showed the value as 2.00-4.20 ppm. The result proved that the commercial Yadong sold in the market contained total phenolic compound and resveratrol .
\end{abstract}

Keywords: commercial Yadong , herbal drug , reveratrol, Thai Yadong, Total phenolic content

\section{Introduction}

Thai people used herbal plants to cure the health for a long time. They eat medicinal plants by several methods such as eat fresh plant, drinking the filtrate from boiling water of plants or a liquor from white spirit fermentation and also eat as the pellet called bolus[1]. The other method,some Thai herbs have been used in food as the component of food or as a food additive.[2] However, they also believe in the special properties of medicinal plants as the protection or curing human health such as anti-tumor, immune stimulating properties that may help or reduce the risk of cardiovascular disease and cancer.[3] The rural people in the Northern part of Thailand frequently drink spiritual liquor from Thai medicinal plants by boiling in hot water or fermented with spiritual liquor known as Thai YaDong. The popular medicinal plants that use for making YaDong such as Ficus pubigera Wall., Polygala chinensis Linn., Betula alnoides Buch.-Ham.ex G.Don, Suregada multiflorum Baill. , Brucea javanica (Linn.) Merr. , Albizzin myriophyll, Benth., Cinnamomum verum., Piper sp., Caesalpinia sappan,Linn and Elephantopus scaber Linn. Ficus pubigera Wall., used for sexual tonic, general tonic or blood tonic, relieve physical exhaustion and backache.[4] Polygala chinensis Linn., is traditionally used in the treatment of fever and dizziness [5]. It contains various useful phytoconstituents such as flavonoids, flavone glycosides, lactonic lignans and saponins[ 6-10]. It is also used in treatment of general debility, fever and liver dysfunctions. Polygala chinensis Linn is used for a variety of purposes including the promotion to sleep and calming the spirit. Polygala chinensis Linn considered as a powerful tonic herb[11]that can help to develop the mind and aid in creative thinking. Biological activities such as antidiabetic, antiinflammatory and antioxidant activities were reported[12-13] Betula alnoides Buch.-Ham.ex G.Don is one of the popular plant in many Ya Dong formulars. It benefit in the treatment of diabetes mellitus as $\alpha$-glucosidase inhibitory activity and lowering of the blood glucose levels[14]. Isolation of chemical constituents from Suregada multiflorum has provided various compounds of alkaloids, cardiac glycosides, flavanoid, saponin, terpenoids, lactone and gelonin[15].The chemical constituents from Suregada multiflorum inhibit plant bacterial diseases such as citrus canker and that they would probably be useful for canker prevention in replacing chemical pesticides[16]. Brucea javanica (Linn.)Merr. is a potent anticancer and antimalarial plant.[17] Albizia myriophylla contains two known triterpene saponins, licorice-saponin F3 and yunganoside B1[18]. The example of some referred medicinal plants as above show the properties of medicinal plant for health. There was no reported about the study of resveratrol content of those Thai medicinal plants and Ya Dong.

Resveratrol (3,5,4'-trihydroxystilbene) is a polyphenolic phytoalexin. It is a stilbenoid, a derivate of stilbene as in figure 1[19]., and is produced in plants with the help of the enzyme stilbene synthase. 
<smiles>Oc1ccc(/C=C/c2cc(O)cc(O)c2)cc1</smiles>

Figure 1 Chemical structure of 3,5,4 '-transhydroxstilbene

Resveratrol might be a key ingredient in red wine that helps prevent damage to blood vessels, reduces low-density lipoprotein (LDL) cholesterol and prevents blood clots. Resveratrol was proved in vitro to show the anticarcinogenic activity, prevention the cardiovascular disease[20-21] for people who drank wine.It also synergized with quercetin and ellagic acid in the induction of apoptosis in Leukemia cell[22].As the above referred about the advantage of resveratrol showed that it is good for health. However, resveratrol is used to identified the quality of wine especially in red wine[20].

In general the phenolic compound are also found in many plants, These compounds composes of an aromatic ring bearing one or more hydroxyl groups and their structures may range from that of a simple phenolic molecule to a complex high-molecular weight polymer [23]. The antioxidant activity of phenolic compounds depends on their structure, in particular the number and positions of the hydroxyl groups and the nature of substitutions on the aromatic rings. Fruits, vegetables and beverages are the major sources of phenolic compounds in the human diet.However, the total phenolic content in medicinal plants show a few work such as the total phenolic content was evaluated in Polygala chinensis according to Folin-Ciocalteu reagent which revealed a high amount of polyphenols as $88.2 \pm 9.3 \mathrm{mg} / 100 \mathrm{gm} \mathrm{[24]}$

The aim of this work was to analyse the total phenolic compound content and resveratrol content in ten medicinal plants which compose to be YaDong and YaDong from Thai Wisdom knowledge formula. The commercial YaDongs were also analysed the total phenolic compound content and resveratrol content too.

\subsection{Materials}

\section{Materials And Method}

\subsubsection{Chemicals}

All chemicals used were of analytical reagent grade. Folin Ciocalteau reagent, sodium carbonate , gallic acid were purchased from sigma chemical (USA). White spirit ( Liquor Distillery Organisation Excise Department) was purchased from Lotus super market in Bangkok. The standard 3,5,4-transhydroxstilbene (HPLC grade) was purchased from Sigma. Acetonitrile (HPLC grade), ethanol (AR grade), methanol (AR grade),sodium sulphate anhydrous (AR grade) were purchased from Carlo Erba.Gracial acetic acid (AR grade) was purchased from Merck.

\subsubsection{Plant materials}

The dried bark or leaves from ten types of medicinal plants such as Ficus pubigera Wall., Polygala chinensis Linn., Betula alnoides Buch.-Ham.ex G.Don, Suregada multiflorum Baill. , Brucea javanica (Linn.) Merr. , Albizzin myriophyll, Benth., Cinnamomum verum., Piper sp., Caesalpinia sappan,Linn and Elephantopus scaber Linn.were purchased from the local market of Nan Province(Thailand).

\subsubsection{Commercial YaDong}

Commercial Yadong samples were purchased from Bangkok, Nakornpathom and Ubonratchathanee province in Thailand.

\subsection{Method}

2.2.1. Preparation of Analytical Samples: Each medicinal plants (10 g.) was placed in the $100 \mathrm{ml}$ of $80 \%(\mathrm{v} / \mathrm{v})$, ethanol, covered with gross cloth and glass lid and stored for 30 days.Then mixed 10 medicinal plants ( $10 \mathrm{~g}$, each) and fermented with $80 \%(\mathrm{v} / \mathrm{v})$, ethanol, do the same as fermented each plant.The mixing sample was laboratory Yadong ( fermented with ethanol).Each plant and mixing plants were treated again with white spiritual liquor. The last mixing plants in white spiritual was the laboratory Yadong in white spirit.

2.2.2 Analysis of total phenolic compound. The analysis method modified from [25], the clear filtrates from part 2.2.1 were pipetted $0.4 \mathrm{ml}$ and mixed with $2 \mathrm{ml}$ of $10 \%$ Folin Ciocalteau reagent(AR) and $1.6 \mathrm{ml}$ of 7.5 $\%(\mathrm{w} / \mathrm{v}) \mathrm{Na}_{2} \mathrm{CO}_{3}$ and left at room temperature for 30 minutes. The mixing solution was measured an absorbance at $765 \mathrm{~nm}$ by Ultraviolet Visible Spectrophotometer( UV -VIS Shimadzu Model UV100) and calculated total 
phenolic compound content as gallic acid equivalent by comparison with standard calibration curve. The commercial Yadong samples were treated as above and also calculated total phenolic content as gallic acid.

2.2.3Analysis of Resveratrol content . All samples in part 2.2.1 were filtered with filter paper(Whatman no.1) and collected the filtrate.The filtrate were clarified again with cellulose nitrate filter $(0.2 \mu \mathrm{m})($ Whatman $)$ and injected through the RP C18 guard cartridge, sent to Hypersil ODS (C18) column $(5 \mu \mathrm{m})(4 \mathrm{x} 125 \mathrm{~mm})$ of high performance liquid chromatography(HP1100, Agilient) and eluted by methanol : $5 \%$ (v/v) acetic acid (1:1) as isocratic gradient system. The signal was detected by UV detector at $306 \mathrm{~nm}$. This experimental system was modified from Christine et al.[26].The commercial Yadong 16 samples were treated as above.The area of the resveratrol peak was recorded from the HPLC chromatogram and compared with the standard resveratrol calibration curve to calculate the resveratrol content.

\section{Results And Discussion}

After each medicinal plant was treated with $80 \%(\mathrm{v} / \mathrm{v})$ ethanol solution for 30 days, the residue plant was filtered out and the collected filtrate was analysed follow up as part 2.2.2. The standard gallic acid solutions were recorded the absorbance after the complex formation at $765 \mathrm{~nm}$. The standard calibration curve of standard gallic acid solution was prepared as the Fig.2.

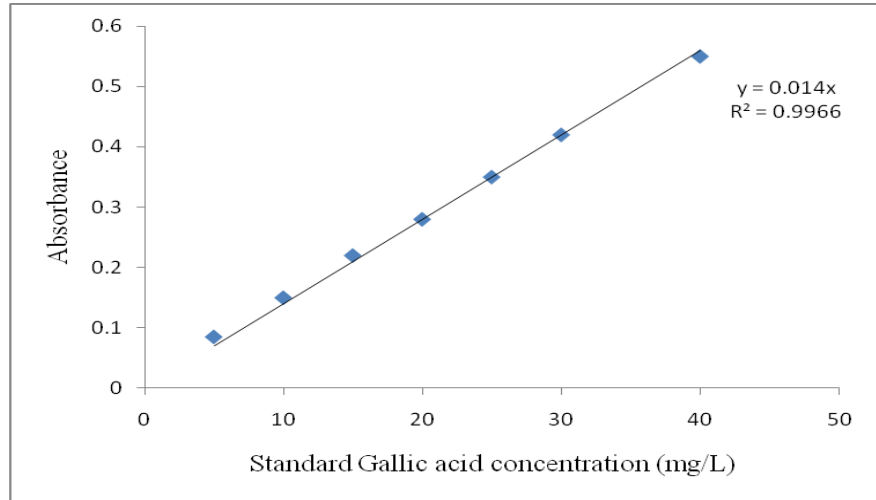

Figure 2 Standard calibration curve of standard gallic acid

The result of the total phenolic content in each medicinal plant that extracted by $80 \%$ ethanol and white spiritual liquor showed in Fig.3.

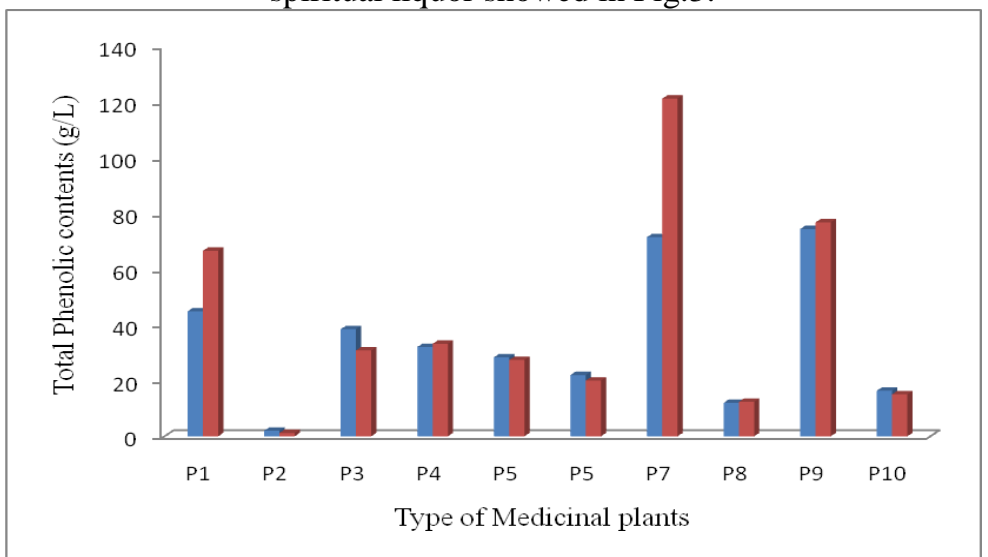

Figure 3. Total phenolic compound content of each medicinal plant

Note: Represent the total phenolic compound content in each plant that extracted with $80 \%$ ethanol Represent the total phenolic compound content in each plant that extracted with white spirit Liquor

$\mathrm{P} 1=$ Ficus pubigera Wall.,

P2= Polygala chinensis Linn.,

P3= Betula alnoides Buch.-Ham.ex G.Don, P4= Suregada multiflorum Baill. ,

P5= Brucea javanica (Linn.) Merr. , $\quad$ P6= Albizzin myriophyll, Benth.,

P7 = Cinnamomum verum.,

8= Piper sp.,

$\mathrm{P9}=$ Caesalpinia sappan, Linn

$\mathrm{P} 10=$ Elephantopus scaber Linn 
From the total phenolic compound content of each plant that extracted by both solvent showed the same trend. The Cinnamon verum. that extracted with white spirit liquor contain the highest total phenolic content as $120 \mathrm{~g} / \mathrm{L}$ and the Polygala chinensis Linn., contained the least total phenolic content as $2 \mathrm{~g} /$ Lor 200mg/100 ml.However, this result also confirmed with the results from [24] that the Polygala chinensis Linn.,also contain total phenolic substance. The difference results may from the sample of Polygala chinensis Linn., that growth in difference status. There was no data about the phenolic content in other medicinal plants. Thus, this total phenolic compound content data of the medicinal plants also presented that all plant have an importance chemical substance in its but the total phenolic compound quantities also depend on the condition for extraction.

The filtrate of each plant was analysed the resveratrol content as part 2.2.3. The standard resveratrol was prepared standard calibration curve as Fig.4.This validation method showed the LOD at $0.03 \mathrm{ppm}$.

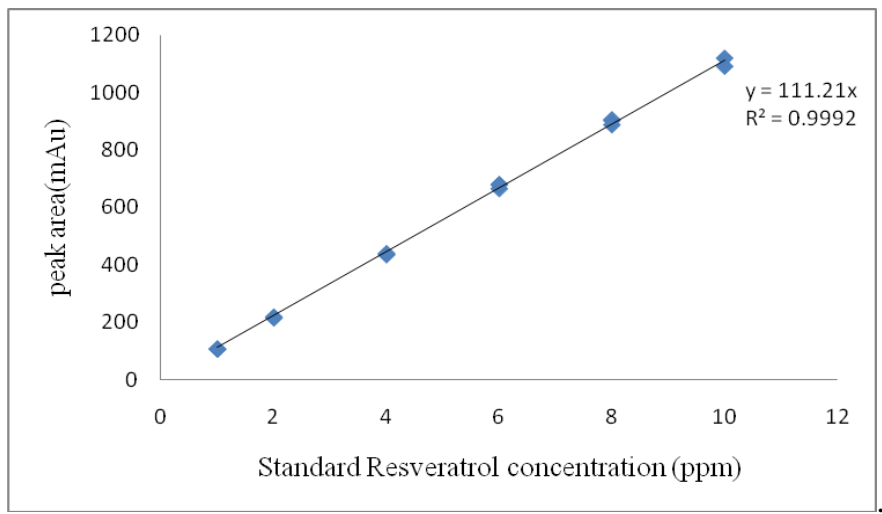

Figure 4 Standard calibration curve of standard resveratrol

The resveratrol content from each plant showed in Fig.5.

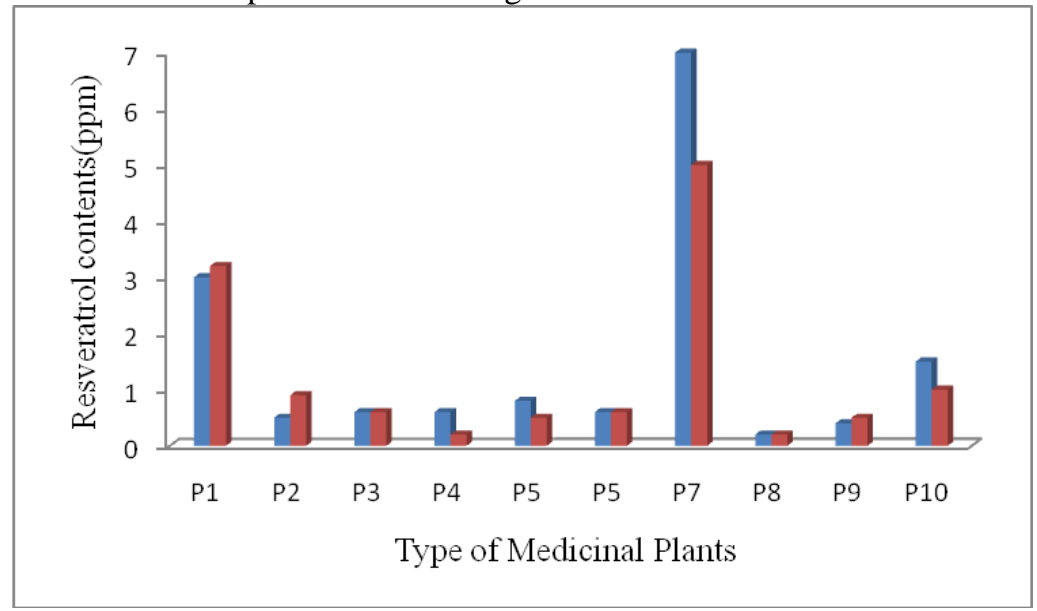

Figure 5. Resveratrol content of each medicinal plant

Note: Represent the total phenolic compound content in each plant that extracted with $80 \%$ ethanol Represent the total phenolic compound content in each plant that extracted with white spirit Liquor $\mathrm{P} 1=$ Ficus pubigera Wall.,

P3 = Betula alnoides Buch.-Ham.ex G.Don, $\mathrm{P} 4=$ Suregada multiflorum Baill.,

P5 = Brucea javanica (Linn.) Merr. , $\quad$ P6 = Albizzin myriophyll, Benth.,

$\mathrm{P} 7=$ Cinnamomum verum.,$\quad \mathrm{P} 8=$ Piper spp.

$\mathrm{P} 9=$ Caesalpinia sappan, Linn $\quad \mathrm{P} 10=$ Elephantopus scaber Linn.

The P7 which was a Cinnamomum verum., also showed the maximum resveratrol content like the result from analysis of total phenolic content. This mean that resveratrol may be an important compound in Cinnamomum verum., too. The P8 which was Piper spp. contained the lowest amount of resveratrol.

After mixed all 10 type of medicinal plants and treated as the part 2.2.1(that called laboratory YaDong), the total phenolic compound content and resveratrol content were done by the same way. The commercial YaDong ( 16 samples ) were also analysed too. The result showed in Fig.6 and 7 respectively. 


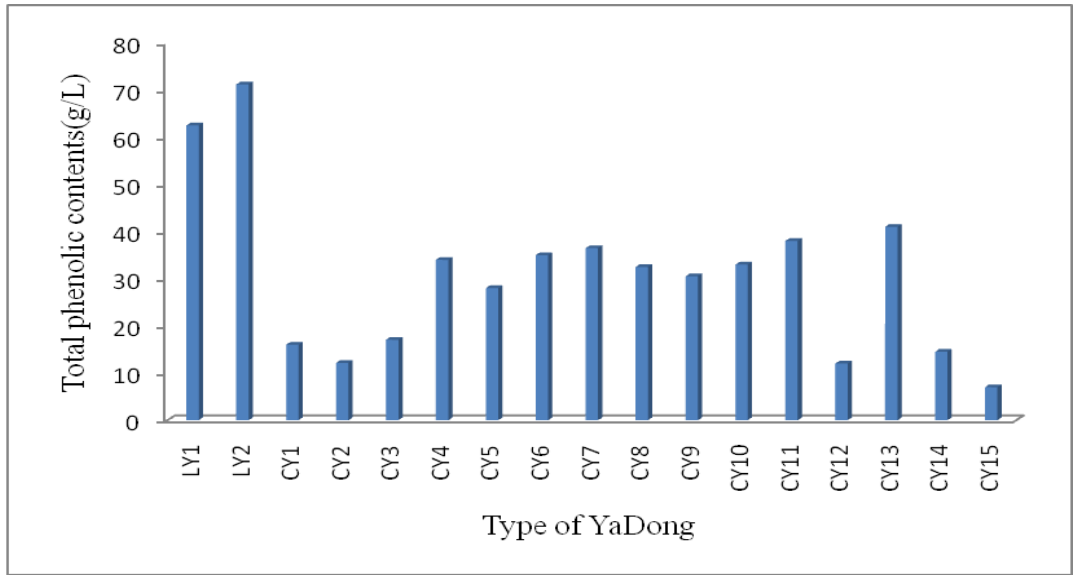

Figure 6. Total phenolic compound content of each YaDong

Note : LY1 = laboratory YaDong sample ( medicinal fermented in $80 \%$ ethanol solution) LY2 = laboratory YaDong sample ( medicinal fermented in white spiritual liquor) CY1 - CY16 = commercial YaDong samples

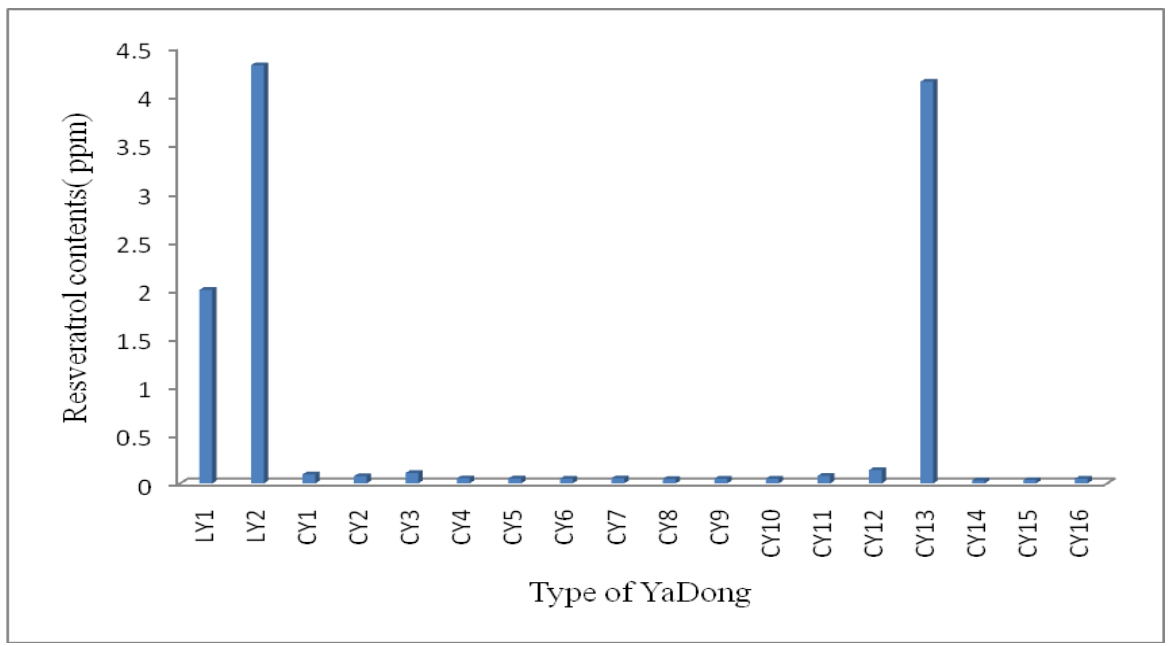

Figure 7. Resveratrol content of each YaDong

Note : $\mathrm{LY} 1=$ laboratory YaDong sample ( medicinal fermented in $80 \%$ ethanol solution)

LY2 = laboratory YaDong sample( medicinal fermented in white spiritual liquor)

CY1 - CY16 = commercial YaDong samples

From the value of total phenolic compound content in each YaDong sample in Fig.6 showed that the YaDong which prepared in our laboratory presented the higher content than found in all commercial YaDong.This may from the preparatory YaDong in our laboratory more concentrated than the commercial YaDong. As the reason about the policy of this business, the YaDong in commercial vessel also be diluted with white spirit liquor whenever the liquid reduce in volume.Then, the resveratrol content in laboratory YaDong also same trend as the total phenolic compound content. The noticed point that the CY13 which was a commercial YaDong showed the high level of resveratrol.The CY13 which was YaDong from only one type of herb plant that labeled as Andrographis paniculata (Burm.f.) Wall.ex Nees.This Andrographis paniculata (Burm.f.) Wall.ex Nees. traditionally used to treat infections and some diseases concerning inflammatory[27] and was also listed as one type of popular medicinal plant of Thai wisdom knowledge. The major constituent extracted from the leaves of this plant which is a bicyclic diterpenoid lactone which was known as andrographolide[28]. Andrographolide is a member of the isoprenoid family of natural products, that could be changed to substituted phenolic compound in some plant[29].Thus, it is a good idea to prepared YaDong from Andrographis paniculata (Burm.f.) Wall.ex Nees. YaDong that made from Andrographis paniculata (Burm.f.) Wall.ex Nees sold in some location not distribute through Thailand.In general ,Thai YaDong has many formulars depend on the zone or part of country, the type of medicinal plant, the time for fermentation of 
YaDong, the quantity of white spiritual liquor. From Thai Wisdom knowledge, the northern part of Thailand can collected the YaDong from Thai medicinal for many formulars.

\section{Conclusion}

The results from this work presented that each medicinal plant that extracted by ethanol and white spiritual liquor contained the total phenolic compound in the range of $2.00-74.42 \mathrm{~g} / \mathrm{L}$ and $1.20-76.82 \mathrm{~g} / \mathrm{L}$ ,respectively. The 10 medicinal plants also has an important substance as resveratrol in the range of $0.2-7$ ppm.After, all plants were mixed together and fermented in ethanol and white spiritual liquor to prepare as laboratory.The laboratory YaDong showed the higher value of total phenolic compound content than commercial YaDong.The total phenolic compound content in laboratory YaDong was in the range of $62.50-$ $71.20 \mathrm{~g} / \mathrm{L}$, the commercial YaDong has the total phenolic compound in the range of 5.00-41.00 g/L.The resveratrol content in laboratory YaDong also showed the value as $2.00-4.20 \mathrm{ppm}$ which higher than the resveratrol in commercial YaDong except the commercial YaDong made from Andrographis paniculata (Burm.f.) Wall.ex Nees.This research proved that Thai YaDong has high quality to drink which they contained the total phenolic compounds and the importance substance as resveratrol.The resveratrol is now an index quality for wine products.Now, it may be use an index to refer the quality of Thai YaDong from Thai Wisdom Knowledge.

\section{Acknowledgements}

The authors wish to thank the Strategic Wisdom and Research Institute of Srinakharinwirot University for University funding and research affair for Faculty of Science,Srinakharinwirot University to support the fund in this research work.

\section{References}

[1]. Y.Wang, F.Catana , Y.Yang,R.Roderick ,RB.Van Breemens ,Journal of Agricultural and Food Chem, 50 ,2002,431-435.

[2]. P.Attakorn, S.Suphan, L. Tamaporn,P. Paweena and W. Viroj ,Inhibition of Heinz Body Induction in an in Vitro Model and Total Antioxidant Activity of Medicinal Thai Plants. Asian Pacific.Journal of Cancer Prevention,6,2005,458-463

[3]. WJ.Craig . Health-promoting properties of common herbs.The American Journal of Clinical Nutrition ,7093 ,1999,491-499.

[4]. TK.Sur, S.Pandit, DBattacharyya , CK .Kumar, SM.Lakshmi ,D. Chatttopadhyay ,SC. Mandal ,Studies on the antiinflammatory activity of Betula alnoides bark. Phytotherapy Research,16,2002,669-671.

[5]. KR. Kirtikar and BD.Basu ,Indian Medicinal Plants, International Book Distributors, Dehradun, 1956

[6]. S. Ghosal ,RPS. Chouhan and RS.Srivastava . Structure of chinensin: a new lignan lactone from Polygala chinensis., Phytochemistry, 13,1974,2281-2284.

[7]. S. Ghosal, RPS.Chouhan and RS.Srivastava, Two new aryl napthalide lignans from Polygalachinensis. Phytochemistry, 13, 1974, 1933-1936.

[8]. S. Ghosal ,RPS. Chouhan and RS.Srivastava , Lactonic lignans of Polygala chinensis., Phytochemistry,12, $1973,2550-2551$.

[9]. MS.Rao,PS. Rao,JK. Kumar and NV.Raman. A rare flavonol glycoside from Polygala Chinensis, Biochemical Systematics and Ecology,31(6),2003,635-636.

[10]. MS.Rao and MV.Raman, A novel flavonoid from Polygala Chinensis. Biochemical Systematics and Ecology,32(4), 2004,447-448.

[11]. M.Alagammal, K.Rajalakshmi and VR. Mohan ,Antidiabetic and antihyperlipidiaemic activity of Polygala chinensis L.whole plant in alloxan induced diabetic rats. International Journal of Chemical and Pharmaceutical Sciences,3, 2012,37-44.

[12]. M.Alagammal,ED.Daffodil and VR. Mohan ,Anti-inflammatory activity of Polygala chinensis L. whole plant(Polygalaceae). International Journal of Chemical and Pharmaceutical Sciences, 3, 2012,19-21.

[13]. K.Rajalakshmi and VR.Mohan ,Antioxidant properties of Polygala chinensis L. whole plant on alloxan induced diabetic rats. International Journal of Pharmaceutical Sciences and Research ,4,2013, 330-334.

[14]. Y.Pongpiriyadacha, P. Nuansrithong and D.Chantip. Antidiabetic Activity of The Methanolic Extract from Betula alnoides BuchHam. ex G. Don. Journal of Applied Sciences Research ,9(12),2014,6185-6188.

[15]. B.Das and K. Chakravarty.,Three flavones glycosides from Gelonium multiflorum.Phytochemistry, 33(2), 1993 , $493-496$.

[16]. S, Khuntong and W.Sudprasert, Extraction and Basic Testing for Antibacterial Activity of the Chemical Constituents in Suregada multiflorum.Kasetsart Journal. (Nat. Sci.), 42 ,2008, 429 - 434

[17]. SC. Sharma and VK. Agarwal ,Brucea javanica (Linn.)Merr. : a potent anticancer and antimalarial plant : a review. Indian Journal of Pharmaceutical Sciences,55(3),1993,77-85.

[18]. M. Yoshikawa, T.Morikawa, K. Nakano,Y. Pongpiriyadacha, T.Murakami, and H.Matsuda, Characterization of New Sweet Triterpene Saponins from Albizia myriophylla. Journal of Natural Product,65(11), 2002, 1638-1642.

[19]. L.Camont , CH.Cottart,Y. Rhayem, V.Nivet-Antoine, R.Djelidi , F.Collin,JL. Beaudeux, D. Bonnefont-Rousselot ,Simple spectrophotometric assessment of the trans-/cis-resveratrol ratio in aqueous solutions, Analytical Chimica Acta ,634 (1),2009, 121128.

[20]. Y.Wang, F.Catana , Y.Yang ,R. Roderick and RB.van Breemen , An LC-MS method for analyzing total resveratrol in grape juice, cranberry juice, and in wine. Journal of Agricultural and Food Chemistry ,50 (3),2002, 431-435.

[21]. JR. Stewart, MC.Artime and CA.O'Brian, Resveratrol: a candidate nutritional substance for prostate cancer prevention . Journal of Nutrition, 133 (7 Suppl),2003, 2440S-2443S

[22]. N.Balasundram, K. Sundram and S. Samman,, Phenolic compounds in plants and agro-industrial by-products: Antioxidant activity, occurrence, and potential uses. Food Chemistry,99(1),2006,191-203.

[23]. V. Lattanzio, M.Veronica ,T. Lattanzio and A. Cardinali. Role of phenolics in the resistance mechanisms of plants against fungal pathogens and insects .Phytochemistry: Advances in Research, 2006: 23-67

[24]. S. Gurav, N. Deshkar, V. Gulkari, N. Duragkar a, A. Patil, Free Radical Scavenging activity of Polygala Chinensis Linn. Pharmacology online 2,2007,245-253.

[25]. C.Murthy, Antioxidant activity of grape (Vits vinifcra) pomace extracts .Journal of Agricultural and Food Chemistry.50,2002,5909-5914. 
[26]. C.Christine, C.Delphine and C.Sonia,Chocolate and cocoa: New sources of trans-resveratrol and trans-piceid, Food Chemistry, 98,2006,649-657.

[27]. K.Sheeja, PK.Shihab and G.Kuttan, Antioxidant and anti-inflammatory activities of the plant Andrographis paniculata Nees. Immunopharmacology and immunotoxicology, 28 (1),2006, 129-140.

[28]. YF. Xia, Ye. BQ, YD. Li, JG.Wang, XJ.He, X.Lin, X.Yao ,D.Ma ,A.Slungaard, RP.Hebbel, NS.Key, JG.Geng, Andrographolide attenuates inflammation by inhibition of NF-kappa B activation through covalent modification of reduced cysteine .Journal of immunology, 173 (6),1950, 4207-4217.

[29]. T.Nomura and Y. Hano, Isoprenoid-substituted phenolic compounds of moraceous plants, Natural Product Report,11,1994, 205218. 